\title{
Transpersonal Caring Relationship
}

\author{
Joyce Reder* \\ Department of Nursing, Saginaw Valley State University, USA \\ *Corresponding author: Joyce Reder, Department of Nursing, Saginaw Valley State University, USA. \\ To Cite This Article: Joyce Reder. Transpersonal Caring Relationship. Am J Biomed Sci \& Res. 2019 - 3(1). AJBSR.MS.ID.000631. \\ DOI: 10.34297/AJBSR.2019.03.000631
}

Received: May 09, 2019 | Published: May 16, 2019

\section{Introduction}

The enduring values and beliefs that brought me to nursing include a desire to have purpose in my life. This means I want to know that I did not waste my time on earth. Another belief is that every person deserves to be cared for by compassionate caregivers. My compassion for others comes from my belief in all people being children of God. My religious values are the most important beliefs I hold. Faith gives people a reason for everything they do. I believe we will be judged by God at the end of our time on earth and I want to be worthy of redemption. Caring for those who are sick or cannot care for themselves is, in my opinion, helping to do God's work. Hopefully this work will assist in my being judged favorably.

This work is also valuable to society. Civilized societies take care of their members who are disabled, ill, and handicapped. Nursing can be very difficult at times. Nurses clean up feces, emesis, and blood. They sometimes bear the brunt of angry and hopeless outbursts caused by illness. They witness patient's lives ending and sometimes are there when parents lose their children to accidents and disease. These tasks are part of the needs of society. These values and beliefs I bring to every nursing situation.

According to Parker \& Smith [1], nursing's metaparadigm consists of four domains. These domains are nurse, person/s, health, and environment. Insights gained regarding these realms include that we are all connected. Our humanness and the fact that we live our lives in societies and not as solitary beings help us to have empathy and compassion for others. According to Watson (1985), this connectedness guides our caring. It affirms nursing's "professional ethic and mission to society-its raison d'être for the public." [1]. I am realizing more profoundly as I acquire higher education and with maturity that we are cosmically connected through a belief in God. Working as a nurse it is, at times, difficult to find a purpose for all the suffering you witness. Without faith and the belief that there is something worthwhile waiting for us after we die, this profession could become very discouraging.

The transpersonal caring relationship is part of the nursing philosophy used in my practice setting. This theory becomes stronger with the wisdom that comes with age and with years of experience working with patients, some of whom had untreatable conditions. Even as a young nurse, however, I was concerned with my patient's holistic well-being and not just the physical dimension of their care.
An example of this is a patient I cared for at a long-term acute care hospital in 1997. Jeanie was in her late sixties. She had had diabetes for many years and her kidneys had failed, and she now needed dialysis every other day. She was in the hospital because she recently had a stroke leaving her paralyzed on the right side. She had also developed a pressure ulcer on her coccyx secondary to her immobility and incontinence.

Jeanie had been married to a man for over forty years, but he had passed away several years earlier. She had no children. In the several weeks she was a patient at this facility, she never had a visitor. Jeanie endured several pokes to assess her blood glucose level every day and painful daily dressing changes for her wound. She tried to put on a brave face when painful procedures had to be completed and she never complained. She rarely used the call bell and was very kind to all her caregivers. She did not speak well due to the paralysis caused by the stroke, but she could be understood. As I got to know Jeanie, I began to request her for my patient on the nights that I worked. As the days went by, I could see Jeanie's health was declining and that she was losing the will to live. I asked her if I could read to her. She requested I read certain passages from the Bible. At the time, I felt this may help her find meaning in her existence. She was always very grateful, and I read to her whenever I could.

One night when I came in for my shift, I was informed by her day nurse that Jeanie had refused to go to dialysis and had stated she would not go any more. Jeanie and I discussed this that night and she made me understand that she was aware of the consequences of the decision. We read the Bible several more nights and Jeanie seemed to be at peace. Then one night when I came on for my shift, I learned that Jeanie had passed away. I felt sad and that I would miss her, but I also felt that I might have helped her just with my presence and caring about her. This experience improved me as a nurse. Our relationship went beyond nurse/patient to transpersonal. I also felt like this experience helped me as a person. It made me feel as though I serve a valuable purpose in the world.

\section{References}

1. Parker ME, Smith MC (2010) Nursing Theories and Nursing Practice. Jean Watson's theory of human caring, ( $3^{\text {rd }}$ edn), Davis Company, Philadelphia pp. 1-565. 